\title{
Fatores Associados à Criminalidade Violenta no Brasil
}

\section{Factors Associated with Violent Crime in Brazil}

\author{
Diego Pierotti Procópio* \\ Silvia Harumi Toyoshima**
}

Resumo: Objetiva-se neste estudo avaliar quais fatores estão associados à criminalidade violenta no Brasil. As categorias de crimes selecionadas foram as de homicídios, latrocínio e lesão corporal dolosa seguida de morte. Para a realização deste estudo é utilizado o modelo econométrico na estrutura de dados em painel para todas as unidades federativas brasileiras. Os resultados indicam que o modelo de efeitos fixos é o mais adequado. Além disso, constata-se que o mercado de drogas e a taxa de desemprego influenciam positivamente as taxas de crimes analisadas. Por outro lado, as políticas socioassistenciais ofertadas pelos Centros de Referência de Assistência Social (Cras) têm contribuído para a melhoria da qualidade de vida de diversas famílias brasileiras que vivem em situação de vulnerabilidade socioeconômica, e, com isso, tal medida governamental tem colaborado para o combate da criminalidade violenta no país.

Palavras-chave: Criminalidade violenta. Mercado de drogas. Dados em painel.

\begin{abstract}
The objective of the present study was to evaluate which factors are associated with violent crime in Brazil. The categories of crimes were selected homicide, robbery and willful corporal lesion followed by death. For this study we used the econometric model in the data structure in panel for all Brazilian federal units. The results indicated that the fixed effects model is the most suitable. In addition, it was found that the drug market and the unemployment rate positively influence analyzed crime rates. On the other hand, social assistance policies offered by Social Assistance Reference Centres have contributed to improving the quality of life of many Brazilian families living in situation socioeconomic vulnerability and, therewith, such a government measure has contributed to the fight against violent criminality in the country.
\end{abstract}

Keywords: Violent criminality. Drug market. Panel data.

JEL Classification: K42.

Mestre em Economia pela Universidade Federal de Viçosa (UFV). Professor do Departamento de Zootecnia e Extensão Rural (DZER) da Universidade Federal de Mato Grosso (UFMT). E-mail: diego.procopio@ufv.br

** Doutora em Ciência Econômica pela Universidade Estadual de Campinas (Unicamp). Pós-doutora pela University of Illinois. Professora titular do Departamento de Economia da Universidade Federal de Viçosa (UFV). E-mail: htsilvia@ufv.br 


\section{1 lntrodução}

Após a implantação do Plano Real, houve uma melhoria generalizada dos indicadores sociais, bem como um fortalecimento das instituições democráticas brasileiras. Ocorreu um aumento da expectativa de vida do brasileiro. A taxa de mortalidade infantil baixou drasticamente, o número médio de anos de estudo aumentou, além da melhoria das condições sanitárias das casas brasileiras. Após mais de 16 anos de continuidade da mesma política econômica e de um ambiente de estabilidade e crescimento, a tendência é que tais indicadores melhorem ainda mais (BEATO FILHO, 2012).

Em contraste com a melhora dos indicadores sociais, no Brasil há registros de que ocorreu um aumento na criminalidade nas últimas décadas. Dentre as várias modalidades de crimes, pode-se destacar a de homicídios. Em 1980, a taxa brasileira era de 11,73 homicídios para cada 100 mil habitantes, aumentando para 22,16, em 1990, e alcançando o ápice, em 2003, com um valor de 28,26 mortes para cada 100 mil pessoas. No ano de 2011, a taxa desse tipo de crime foi de 27,40, e, além disso, no período de 1980 a 2011 foram registrados mais de 1 milhão de assassinatos no país (BRASIL, 2014a).

Aparentemente, o que está acontecendo é um paradoxo: o incremento dos indicadores sociais, bem como a estabilidade das instituições políticas encontram incômoda companhia no crescimento das taxas de criminalidade urbana (PAIXAO, 1988). Esse contraste na evolução negativa da segurança pública ocorreu justamente num período de melhoria generalizada dos indicadores sociais, sendo necessária a investigação das causas e fatores associados à expansão das taxas de homicídios nas localidades brasileiras (BEATO FILHO, 2012).

$\mathrm{Na}$ literatura nacional encontram-se diversos fatores que explicam as causas para o agravamento da criminalidade no país, podendo-se destacar:

a) a exclusão e a desigualdade socioeconômicas das regiões, estados e municípios que resulta numa diferenciação no padrão de vida dos brasileiros (SERRANO-BERTHET; CHIODA, 2012; FAJNZYLBER; ARAÚJO JUNIOR, 2001; SACHSIDA et al., 2009; PEREIRA; FERNANDEZCARRERA, 2000; LOBO; FERNANDEZ-CARRERA, 2005; LEMOS; JORGE; SANTOS FILHO, 2005; OLIVEIRA, 2005);

b) o processo brasileiro de urbanização, dado que contribui para a piora da qualidade de vida das camadas mais pobres da população (SACHSIDA et al., 2009; BEATO FILHO, 2012);

c) a má alocação dos recursos públicos em setores como o de educação (FANJZYLBER; ARAÚJO JÚNIOR, 2001; LOBO; FERNANDEZ-CARRERA, 2000; SANTOS, 2009; OLIVEIRA, 2005) e segurança (FANJZYLBER; ARAÚJO JÚNIOR, 2001; PEREIRA; FERNANDEZ-CARRERA, 2000); 
d) o crescimento e a organização do crime, principalmente os relacionados ao comércio de drogas ilícitas (BEATO FILHO; REIS, 2000; SANTOS; KASSOUF, 2007; UHR; ZIERO, 2011).

Os significativos aumentos nas taxas de criminalidade, os elevados custos associados ao crime e a crescente importância dada ao assunto têm levado os governos e a sociedade em geral a considerar o problema da criminalidade como um dos mais sérios obstáculos ao desenvolvimento econômico e social. O desafio é formular e implementar políticas que permitam prevenir e reduzir a ocorrência do crime e da violência. Para tanto, é de fundamental importância o desenvolvimento de pesquisas que permitam avançar na compreensão das causas desse problema social que se agrava cada vez mais no país (LOUREIRO; CARVALHO, 2006).

Neste estudo são avaliados os crimes violentos, que, de acordo com o Código Penal Brasileiro, são: homicídios e estupros tentados e consumados; extorsão mediante sequestro; latrocínio; roubo à mão armada; roubo sem arma; sequestro e cárcere privado (BRASIL, 1940). No entanto, nesta pesquisa serão entendidos por criminalidade violenta apenas os crimes que resultam em perda de vida da vítima, que são os delitos de homicídios, latrocínios e de lesão corporal seguida de morte. As informações das taxas de crimes foram retiradas do Anuário Brasileiro de Segurança Pública dos anos de 2009, 2010, 2011, 2012 e 2013, organizado pela Secretária Nacional de Segurança Pública (Senasp).

A partir de tais discussões, levantam-se algumas indagações: por que, apesar da melhoria dos indicadores sociais brasileiros, houve um aumento expressivo da criminalidade no país? O crime organizado teria alguma relação com a expansão da criminalidade violenta no país, principalmente pela expansão do mercado de drogas? Este estudo busca responder tais questões, contribuindo, assim, para a avaliação de quais fatores estariam associados ao aumento da criminalidade violenta no país, uma vez que houve melhoria nas condições socioeconômicas da população.

Com isso, objetiva-se avaliar quais fatores estão associados à criminalidade violenta no país. Para a análise, são selecionadas todas as unidades federativas brasileiras e o período de 2008, 2009, 2011 e 2012. A escolha por esse intervalo temporal é baseada em duas justificativas: por causa da disponibilidade de informações das taxas criminais e porque as informações socioeconômicas brasileiras do ano de 2010 é proveniente do censo demográfico, que utiliza uma metodologia diferente da Pesquisa Nacional por Amostra de Domicílios (PNAD), que é a base de dados utilizada para os demais anos do período analisado.

Na sequência do trabalho, na segunda seção é apresentado o referencial teórico, na terceira é apresentado o procedimento metodológico utilizado e, por fim, nas duas últimas seções são discutidos os principais resultados alcançados e apresentadas as considerações finais do estudo. 


\section{Referencial Teórico}

A Economia é apenas umas das diversas áreas de conhecimento que se dedicam ao entendimento do crime. Algumas outras ciências também se interessam pelo estudo desse tema, dentre as quais se destacam a Demografia, a Saúde Pública, a Sociologia e a Ciência Política. Como na Economia, tais áreas possuem em comum o objetivo de identificar quais as causas motivadoras dos delitos, de modo a subsidiar ações de combate à criminalidade, de forma mais efetiva na sociedade (SANTOS; KASSOUF, 2008).

Para Cano e Santos (2001), as abordagens teóricas sobre as causas da criminalidade são, especificamente: a) teorias centradas no homo economicus, isto é, o crime é entendido como uma atividade racional de maximização de lucro; b) linhas teóricas que entendem a criminalidade como um resultado da perda do controle e da desorganização social na sociedade moderna; c) teorias que consideram o crime como um subproduto de um sistema social perverso ou deficiente; e d) teorias que creditam que a ocorrência do ato criminoso seria o resultado de fatores situacionais ou de oportunidades. Essas linhas teóricas são discutidas nas próximas subseções.

\subsection{Teoria da Escolha Racional}

O modo de ver a atividade criminosa como uma escolha racional de maximização de lucro dos indivíduos foi iniciado por Gary Becker (1968), em seu artigo seminal Crime and punishment: na economic approach, conhecida como a Teoria da Escolha Racional. A presença de atividades ilícitas lucrativas em determinadas localidades, como o mercado de drogas, poderia influenciar a decisão do indivíduo a ingressar ou não na criminalidade.

No estudo, Becker (1968) faz uso da análise de escolhas dos indivíduos em cometer ou não o crime, da qual o ato criminoso decorreria de uma avaliação racional do indivíduo em torno dos benefícios e custos esperados pelo crime, comparados aos resultados obtidos no mercado de trabalho legal. Cerqueira e Lobão (2004) apresentam uma discussão sobre o modelo proposto por Becker. Os autores relatam que a decisão de cometer ou não o crime seria o resultado de um processo de maximização da utilidade esperada do indivíduo. Esse processo de escolha seria resultante da avaliação dos potenciais ganhos do ato criminoso, do valor da punição e das probabilidades de detenção e aprisionamento, em detrimento do custo de oportunidade de cometer o crime representado pelo salário alternativo no mercado de trabalho.

A relação proposta por Becker (1968) é apresentada de forma sucinta através da equação 1: 


$$
O_{j}=O_{j}\left(p_{j} ; f_{j} ; u_{j}\right)
$$

em que $O_{j}$ representa o número de ofensas cometidas pelo indivíduo j em determinado período de tempo; $p_{j}$ é a probabilidade de condenação do indivíduo j; $f_{j}$ é a punição do indivíduo $j$ pelo ato criminoso; e $u_{j}$ abrange todas as demais variáveis que podem influenciar na decisão do indivíduo j pelo ato criminoso. As distribuições de $p_{\mathrm{j}}$ e $f_{\mathrm{j}}$ dependem da estrutura de justiça criminal (juiz, júri, promotor, entre outros) com a qual o indivíduo j se depara. Já a distribuição de $u_{j}$ depende das probabilidades de condenação de outras atividades ilícitas concorrentes. Dessa maneira, existe uma possibilidade de substituição entre os tipos de crimes existentes.

Becker (1968) ressalta que apenas os indivíduos condenados são punidos, dessa maneira haverá uma "discriminação de preço" e incerteza com relação ao ato criminoso: caso seja condenado, o indivíduo paga pelo crime cometido; por outro lado, se não for condenado, o indivíduo não paga $f_{j}$ pelo crime $\left(f_{j}=0\right)$. Um aumento em $p_{j}$ e $f_{j}$ reduzirá a utilidade esperada pelo delito e, com isso, haverá uma redução na quantidade de crimes cometidos pelos indivíduos. Ou seja, quanto mais rígido e eficiente for o sistema de justiça criminal de determinada sociedade, menores serão os estímulos dos indivíduos para ingressarem na criminalidade.

Para Becker (1968), fatores positivos como oportunidades de emprego, acesso à educação, bons salários no mercado de trabalho, entre outros, influenciariam o indivíduo a escolher o mercado legal. Por outro lado, os fatores negativos ou dissuasórios (deterrence effects), como o nível da ineficiência do aparato da justiça criminal e da polícia, além do grau de severidade nas punições judiciais, poderiam estimular a entrada do indivíduo no meio ilegal. Além disso, destaca-se que a presença de atividades ilegais lucrativas (como, por exemplo, o mercado de drogas) na sociedade poderia incentivar a entrada do indivíduo na criminalidade, elevando, assim, as taxas de crimes.

Ehrlich (1973) estende a análise de Becker sobre as causas da criminalidade, atribuindo o efeito da distribuição de renda sobre o crime, ao considerar que um maior nível de desigualdade de renda na sociedade estimularia a entrada do indivíduo mais pobre na criminalidade. Para Entorf e Spengler (2000), em sociedades que possuem elevados índices de desigualdade de renda, os indivíduos que estão inseridos nos estratos mais desvantajosos da distribuição de renda teriam menos oportunidades no mercado de trabalho e, com isso, estariam mais dispostos a cometerem delitos. 


\subsection{Teoria da Desorganização Social}

A segunda linha teórica a ser discutida considera o fenômeno da criminalidade como consequência da perda do controle e da desorganização social resultantes do rápido processo de urbanização de uma sociedade. Trata-se da Teoria da Desorganização Social. Essa abordagem teórica debita a maior incidência dos crimes às características socioeconômicas das comunidades, cidades, bairros e vizinhanças.

Na realidade, o mecanismo de causa do crime não se dá de forma direta, mas resulta do fato de que áreas com maior privação relativa e absoluta provocam incrementos na mobilidade e heterogeneidade populacional, conduzindo, assim, a um enfraquecimento dos laços tradicionais de organização social e, consequentemente, gerando um aumento na criminalidade da sociedade. A violência seria o resultado de um processo de frustração de indivíduos privados relativamente na realização de objetivos socialmente legítimos (BEATO FILHO, 2012).

A abordagem sistêmica da desorganização social se relaciona com as comunidades locais, que são explicadas na literatura como um complexo sistema de redes de associações formais e informais, de relações de amizade, parentesco e outras que de alguma forma influenciam no processo de socialização do indivíduo. Essas relações são condicionadas por meio de fatores estruturais, como o status econômico, a heterogeneidade étnica, a mobilidade residencial, a desagregação familiar e o processo de urbanização (SAMPSON; GROVES, 1989).

Bursik e Grasmick (1993) propõem uma abordagem sistêmica que visa explicar as interações dos indivíduos nas comunidades, e que, a partir de tais relações, é determinado o comportamento de tal pessoa em relação ao ato criminoso. As redes sociais são responsáveis por desempenhar a organização social em determinada localidade, sendo subdividida em três níveis e interligadas entre si. O primeiro nível é considerado o mais básico, relacionado com a interação nas redes privadas (ou seja, entre famílias, amigos, vizinhos), pelas quais são transmitidas as expectativas do indivíduo para o comportamento aceitável numa sociedade. É nessa etapa que ocorre a supervisão das crianças e adolescentes realizada pelos pais. O próximo nível para a organização social, definido como paroquial, é representado pela comunidade que tem a capacidade de supervisionar as ações dos residentes e visitantes, cujo controle é exercido por uma rede interpessoal mais ampla (associações de bairro, associações de pais e professores) e através da atuação de instituições locais (igrejas, escolas, organizações voluntárias). Finalmente, o nível público da organização social conecta os laços particulares e paroquiais para um sistema maior de redes incorporadas dentro da estrutura ecológica de uma cidade. O controle público, portanto, é representado pelos serviços necessários à população e os recursos são gerenciados e distribuídos pelas agências externas às 
comunidades. Em geral, esses recursos são limitados e as comunidades locais têm de competir com outros bairros para a aquisição dos serviços públicos.

Para Cerqueira e Lobão (2004), problemas relacionados ao colapso demográfico, ao processo de urbanização descontrolado e ao desajuste social provocado por fatores externos (espaços urbanos deteriorados, comercialização e consumo de drogas ilícitas em lugares abandonados pelo poder público e formação de grupo de jovens intencionados a cometer atos criminosos) e internos (ambientes familiares desestruturados) estariam ligados à origem da criminalidade.

\subsection{Teoria do Controle Social}

A teoria que considera o crime como um subproduto de um sistema social perverso ou deficiente é denominada de Teoria do Controle Social. Para essa linha teórica, o fenômeno da criminalidade decorreria da incapacidade do Estado de prover os meios necessários para que o cidadão tenha uma vida de acordo com os padrões sociais.

Essa abordagem considera que quanto maior for o envolvimento do cidadão no sistema social, e quanto maiores forem os elos da pessoa com a sociedade e maiores os graus de concordância com os valores e normas vigentes, menores são as chances dessa pessoa de cometer atos criminosos (CERQUEIRA; LOBÃO, 2004). Hirschi (1969) relata a importância das escolas na contenção do comportamento delinquente. Para o autor, as escolas proveem oportunidades e incentivos para os jovens desenvolverem uma ligação social com outros jovens e um compromisso com os comportamentos tradicionais de uma sociedade. No entanto, quando as escolas falham na função de agente socializador, aumentam-se as chances de que tais jovens sejam influenciados por outros indivíduos a cometerem atos criminosos.

\subsection{Teoria da Associação Diferencial ou Teoria do Aprendizado Social}

A abordagem teórica que credita a ocorrência do ato criminoso às interações sociais dos indivíduos é denominada de Teoria da Associação Diferencial ou Teoria do Aprendizado Social. A partir de tais interações, surgiriam mais oportunidades para que o indivíduo cometa o ato criminoso.

Essa abordagem considera que os comportamentos dos indivíduos são determinados a partir das experiências pessoais em situações de conflito. Sutherland (1973) ressalta que o comportamento favorável ou desfavorável do indivíduo à criminalidade seria apreendido a partir das interações pessoais (valores, atitudes, definições e pautas em relação ao ato criminoso), com base no processo de comu- 
nicação. Dessa forma, a família, os grupos de amizade e a comunidade desempenham um papel central nesse tipo de análise.

A decisão do indivíduo de seguir o caminho do crime pode ser influenciada, de acordo com a literatura, por uma série de fatores, conforme exposto nas abordagens teóricas anteriores. Pode ser de ordem social, econômica, institucional e política, como a desigualdade na distribuição de renda, a falta de acesso a serviços públicos básicos e a falta de controle da comunidade e do poder público, entre outros fatores que podem afetar a condição de vida das pessoas e a sua interação social.

No entanto, em decorrência do rápido processo de urbanização brasileiro, destaca-se que o crime organizado encontrou espaço para o crescimento e desenvolvimento no país. Glaeser e Sacerdote (1996) relatam que em regiões mais urbanizadas é comum que haja uma maior troca de informações entre grupos de criminosos, implicando, assim, menores custos de planejamento e execução do ato criminoso. Além disso, a qualidade de vida dos mais pobres foi comprometida devido ao déficit no acesso a serviços públicos básicos, como saneamento, educação e saúde. A prática criminosa, como, por exemplo, o mercado de drogas, surge como uma possibilidade de obtenção de recursos para uma melhoria de vida dessa parte da população brasileira excluída socioeconomicamente.

Resignato (2000) observa que a comercialização de drogas ilícitas se relaciona com a criminalidade em diversos aspectos. O primeiro seria em decorrência dos efeitos psicofarmacológicos de dependência química dos usuários para sustentarem o vício, de modo que os indivíduos sujeitos a esse vício estariam dispostos a qualquer atitude para obtenção de recursos para a compra da droga, inclusive o de cometer crimes. Além disso, para o autor, deve-se considerar também a questão econômica e sistêmica desse tipo de mercado, pois a renda econômica gerada pela comercialização de drogas constitui um incentivo para que firmas e traficantes rivais disputem mercados, utilizando a violência como um meio para o alcance dos objetivos.

Para Schelling (1971), no mercado de drogas, a ausência de contratos executáveis faz com que a violência e o medo sejam os mecanismos utilizados para a continuidade da prática criminosa. Tais meios seriam adotados em situações como a punição de membros do próprio grupo de traficantes que tenham realizado comportamentos desviantes ou fraudes, na retaliação de rivais e na realização de cobranças aos usuários devedores.

Além dos fatores de ordem social, econômica, institucional e política que são elencados para explicar o fenômeno da criminalidade, deve-se considerar também a influência dos fatores criminógenos sobre esse fenômeno social, como a presença do mercado de drogas. Na existência de atividades criminosas lucrativas, o indivíduo pode optar pelo meio ilegal para a obtenção de recursos financeiros para uma 
melhora na qualidade de vida. Sendo assim, é necessária a inclusão desse último aspecto para uma análise mais completa da dinâmica da criminalidade no Brasil.

\section{Metodologia}

Nesta seção são descritos os procedimentos metodológicos utilizados e são apresentadas as variáveis selecionadas para a composição do modelo econométrico em questão.

\subsection{Procedimento Econométrico}

A avaliação de quais fatores estão associados ao aumento das taxas de crimes letais intencionais no país é realizada a partir de um modelo econométrico com a estrutura de painel de dados composto por dados de todas as unidades federativas brasileiras para os anos de 2008, 2009, 2011 e 2012. O ano de 2010 não foi levado em conta pela razão de que as informações socioeconômicas desse ano são provenientes do censo demográfico, que apresenta uma metodologia diferenciada da PNAD, que é a base de dados utilizada para os demais anos.

Modelos de dados em painel, ou dados longitudinais, são caracterizados por possuírem observações em duas dimensões, tempo e espaço. Esse tipo de método contém informações que possibilitam uma melhor investigação sobre a dinâmica das mudanças nas variáveis, tornando possível considerar o efeito de variáveis não observadas. Além disso, através desse tipo de metodologia é possível obter uma quantidade maior de informações, maior variabilidade dos dados, menor colinearidade entre as variáveis, maior número de graus de liberdade e maior eficiência na estimação dos parâmetros (MARQUES, 2000).

Nonnenberg e Mendonça (2005) complementam ao relatar sobre a vantagem do emprego de modelos econométricos na estrutura de dados em painel, afirmando que esse método permite levar em consideração as características idiossincráticas (heterogeneidade) existentes entre as unidades estudadas. Greene (2003) relata que nos modelos econométricos de dados em painel admite-se que os erros são distribuídos aleatoriamente com a função densidade, homocedásticos e não autocorrelacionados, o que permite obter estimadores não enviesados e consistentes.

De acordo com Santos e Kassouf (2007), em estudos sobre a criminalidade, as técnicas que exploram as características de dados em painel mostram-se mais apropriadas por permitir o controle da heterogeneidade não observável existente entre as unidades territoriais analisadas, bem como possibilitar o controle parcial do problema de erro de medida decorrente da alta taxa de subnotificação dos registros criminais. Para os autores, é provável que a possibilidade de denúncia do 
crime sofra a influência de outros fatores como o nível de renda, a escolaridade da população, o nível de confiança nas atividades da polícia, entre outros.

A justificativa para o controle da heterogeneidade não observável das unidades federativas brasileiras é atribuída a uma série de fatores, considerando-se que ao longo do território nacional as unidades federativas apresentam características culturais diferenciadas. Podem-se citar, por exemplo, a maior ou menor predisposição a resolver conflitos interpessoais violentamente, disparidade no consumo de bebidas alcoólicas, presença de atividades ilegais lucrativas (mercado de drogas), existência de conflitos associados à posse de terra, entre outros (SANTOS; KASSOUF, 2007; FAJNZYLBER; ARAÚJO, 2001).

A equação básica estimada é representada por:

$$
y_{i t}=x^{\prime}{ }_{i t} \beta+c^{\prime}{ }_{i} a+\varepsilon_{i t}
$$

em que $y_{i t}$ é a oferta de crimes letais intencionais da $i$-ésima unidade federativa $(i=1,2, \ldots, 27)$ no ano $t(t=2008,2009,2011,2012) ; x_{i t}$ corresponde às variáveis explicativas (mercado de drogas; densidade de pessoas por dormitório; famílias chefiadas por mulheres; escolaridade de jovens; taxa de urbanização; taxa de desemprego; renda total apropriada pelo primeiro quintil mais pobre da população; gastos per capita em segurança pública), não incluindo o termo constante; $c^{\prime}{ }_{i} a$ representa a heterogeneidade de cada unidade federativa, em que $c_{i}^{\prime}$ contém um termo constante e variáveis específicas, observáveis ou não, das unidades federativas brasileiras; e $\varepsilon_{\text {it }}$ consiste no termo de erro aleatório.

Há três maneiras de se realizar tal estimação: por meio de regressão pooled, por efeitos fixos (fixed effects) e por efeitos aleatórios (randon effects). Considerando-se que a heterogeneidade possa ser observada para todas as unidades federativas, nesse caso não existem os efeitos não observáveis. Assim, a regressão polled, que é estimada por meio do método dos mínimos quadrados ordinários (MQO), forneceria estimativas consistentes e eficientes (GRENNE, 2003).

No caso da existência da heterogeneidade não observável, é recomendável a utilização de modelos que exploram as características de dados em painel. $\mathrm{Na}$ situação em que a heterogeneidade não observável não for correlacionada com o termo $x_{\mathrm{it}}$, então o modelo de efeitos aleatórios é preferível para se realizar a estimação. Por outro lado, se a heterogeneidade não observável for correlacionada com $x_{i t}$, é preferível a utilização do modelo de efeitos fixos (GRENNE, 2003).

Alguns testes devem ser realizados a fim de se verificar qual o método que mais se ajusta às variáveis analisadas. Primeiro, é necessário testar se realmente a heterogeneidade não observada está presente no modelo a ser estimado. Para isso, Greene (2003) sugere que seja realizado o teste de Chow, baseado na estatística $F$, que confronta os modelos de regressão pooled com o de efeitos fixos, e o teste 
de Breusch-Pagan, que confronta os modelos polled com o de efeitos aleatórios. Caso seja detectada a heterogeneidade não observável, é necessária a realização do teste de Hausman para se verificar qual método é mais adequado, se o de efeitos fixos ou o de efeitos aleatórios.

No caso de modelos de dados em painel são comuns os problemas de autocorrelação e de heterocedasticidade. Para se detectar a presença do primeiro tipo de problema, aplica-se o teste de autocorrelação serial dos erros, proposto por Wooldridge (2002). Já para se verificar a presença de heterocedasticidade no modelo estimado, é necessário aplicar o teste de Wald. Diante da presença de heterocedasticidade e de autocorrelação serial, recomenda-se que seja realizada uma nova estimação do modelo selecionado com erros padrões robustos (GREENE, 2003).

\subsection{Descrição das Variáveis}

A fim de se avaliar o aumento da criminalidade violenta no país, a variável dependente selecionada foi a taxa de crimes letais intencionais para cada 100 mil habitantes das unidades federativas brasileiras. Nela estão inseridas as seguintes categorias de crimes: homicídio doloso, latrocínio e lesão corporal dolosa seguida de morte. Santos e Kassouf (2007) atribuem a vantagem de se utilizar essa categoria de crime devido a menor incidência para o problema de subnotificação.

Na literatura do crime, diversas variáveis têm sido utilizadas para se explicar o fenômeno da criminalidade. Para se verificar qual o efeito da presença de atividades ilícitas lucrativas sobre a criminalidade violenta das unidades federativas brasileiras foram utilizadas as taxas para cada 100 mil habitantes, sendo que os crimes relacionados ao mercado de drogas (posse, uso e tráfico) consiste em uma das variáveis explicativas. Santos e Kassouf (2007) relatam que a presença de atividades ilegais lucrativas elevam os retornos esperados do ato criminoso. Já Fajnzylber, Lederman e Loayza (1998) observam que as atividades ilícitas relacionadas ao mercado de drogas não se limitam apenas à produção e comercialização do produto, mas também envolvem a violência física e corrupção para a manutenção da atividade criminosa. Além disso, deve-se considerar o efeito da droga sobre o comportamento do usuário, que o torna mais propenso ao ato criminoso por conta do vício. Ou seja, espera-se que a presença do mercado de drogas contribua para a elevação nas taxas de crimes letais intencionais das localidades analisadas.

A variável percentual de pessoas que vivem em domicílios com densidade ${ }^{1}$ por dormitório superior a 2 é relacionada à Teoria da Desorganização Social (CERQUEIRA; LOBÃO, 2004). A habitação se configura como uma das mais impor-

$1 \quad$ A densidade do domicílio é dada pela razão entre o total de moradores do domicílio e o número total de cômodos deste, excluídos o(s) banheiro(s) e mais um cômodo destinado à cozinha (IBGE, 2012). 
tantes necessidades do ser humano, uma vez que o tamanho do domicílio interfere na saúde, na segurança e na privacidade dos moradores. Em situações de "congestionamento domiciliar", a qualidade de vida dos indivíduos residentes do mesmo domicílio é afetada (BARBO; SHIMBO, 2006). Sendo assim, espera-se uma relação positiva entre essa variável e o tipo de crime analisado, já que o indivíduo estará mais disposto ao ato criminoso para obter recursos para ter uma melhor condição de vida.

A variável porcentagem de famílias chefiadas por mulheres é atribuída como uma característica de desorganização social (SANTOS; KASSOUF, 2007). De acordo com Kelly (2000), os criminologistas em geral atribuem a relação entre crime e instabilidade familiar a distúrbios emocionais sofridos pelos indivíduos durante o período da infância e adolescência. Além disso, o autor complementa ao relatar que o risco de pobreza é maior nos domicílios com a presença de apenas um dos pais genitores. Dessa maneira, espera-se uma relação positiva entre tal variável com as taxas de crimes letais intencionais das unidades federativas, já que em ambientes familiares conturbados menores serão os "custos morais" do indivíduo em relação ao ato criminoso.

Já a variável de frequência escolar do ensino médio de jovens do sexo masculino com idade entre 15 a 17 anos busca avaliar o efeito do mecanismo de controle social do Estado sobre essa parte da população por meio da educação. Hirschi (1969) relata a importância das escolas na contenção do comportamento delinquente. Para o autor, as escolas proveem oportunidades e incentivos para os jovens desenvolverem uma ligação social com outros jovens e um compromisso com os comportamentos convencionais de uma sociedade. Dessa maneira, espera-se uma relação negativa entre essa variável e as taxas de crimes violentos das unidades federativas.

A taxa de urbanização é dada pela razão entre a população urbana e o total da população das unidades federativas brasileiras. De acordo com Glaeser e Sacerdote (1996), em regiões mais urbanizadas existe uma maior troca de informações entre os grupos de criminosos, implicando, assim, menores custos de planejamento e execução do ato criminoso. Já Cano e Santos (2001) relatam que o maior anonimato das áreas urbanas reduz a capacidade do Estado de estabelecer o controle social e, com isso, incrementa a impunidade dos criminosos. Assim, espera-se uma relação positiva entre essa variável e as taxas de crimes analisadas.

Outra variável utilizada neste estudo é a taxa de desemprego das unidades federativas brasileiras. Para Becker (1968), o incremento na taxa de desemprego resultaria num aumento da criminalidade numa sociedade. A adesão pela carreira criminosa se daria como o resultado de uma escolha inevitável do indivíduo para a realização dos ideais e valores discrepantes em relação aos meios legítimos disponíveis para a realização de tais metas. Por outro lado, Cohen e Felson (1979) complementam ao relatar que o desemprego pode atuar também como um fator 
de diminuição das oportunidades de crime, já que haveria um maior número de guardiães e vigilantes na sociedade. Dessa forma, a priori não é possível estabelecer a relação esperada para a taxa de desemprego com as taxas de crimes violentos das unidades federativas brasileiras.

A variável fração da renda total apropriada pelo primeiro quintil mais pobre da população foi utilizada como mensuração do efeito da desigualdade de renda sobre o nível de criminalidade violenta das unidades federativas brasileiras. De acordo com Entorf e Spengler (2000), em sociedades que possuem elevados índices de desigualdade de renda, os indivíduos que estão inseridos nos estratos mais baixos da estrutura de distribuição de renda possuem menos oportunidades no mercado de trabalho e, com isso, estariam mais dispostos a cometerem delitos. No entanto, devido ao tipo de variável utilizada, espera-se uma relação negativa entre ela e as taxas de crimes analisadas, já que um aumento da renda apropriada pelos mais pobres significaria uma redução na desigualdade de renda das localidades analisadas. Vale citar que tal variável é utilizada também nos estudos de Santos e Kassouf (2007) e Fajnzylber e Araújo Júnior (2001).

De acordo com Balbo e Posadas (1998), a criminalidade é um fenômeno que afeta o bem-estar social e, por isso, a alocação de recursos dos governos no setor de segurança pública combateria tal problema. A variável explicativa utilizada foi a de gastos per capita em segurança pública das unidades federativas brasileiras. De acordo com Santos e Kassouf (2007), quanto maior forem os gastos com segurança pública, maior será a eficiência das atividades preventivas e de combate ao crime. Dessa maneira, espera-se uma relação negativa entre essa variável com as taxas de crimes letais intencionais das localidades analisadas.

Entretanto, ao se utilizar a variável gastos per capita em segurança pública é possível a existência do problema de causalidade reversa, que pode contribuir para a ocorrência da endogeneidade no modelo econométrico estimado. Geralmente, regiões com baixas taxas de crimes tendem a alocar menos recursos públicos em segurança pública comparativamente às regiões que possuem alta incidência de crimes (SANTOS; KASSOUF, 2007). No caso brasileiro, Zaluar (2007) e Beato Filho (2012) atentam para a incapacidade do setor de justiça criminal e segurança pública em atender as demandas nacionais, já que os recursos públicos nesse setor não são aplicados de forma eficaz e eficientemente, indicando, assim, uma possibilidade de não haver o problema de endogeneidade dessa variável no modelo econométrico em questão.

Na Tabela 1 são expostas as informações das variáveis ${ }^{2}$ explicativas e as respectivas relações esperadas com as taxas de crimes letais intencionais das unidades federativas brasileiras.

2 Alguns tipos de variáveis não foram incluídas no modelo econométrico por apresentar uma alta correlação com as demais variáveis explicativas selecionadas. Por exemplo, a taxa de pobreza das 
Tabela 1 - Variáveis selecionadas

\begin{tabular}{|c|c|c|c|}
\hline Variável dependente & Unidade & Terminologia & \\
\hline $\begin{array}{l}\text { Crimes letais } \\
\text { intencionais }\end{array}$ & $\begin{array}{l}\text { Taxa para cada } 100 \\
\text { mil habitantes }\end{array}$ & LETAL & \\
\hline $\begin{array}{l}\text { Variáveis } \\
\text { explicativas }\end{array}$ & Unidade & Terminologia & $\begin{array}{l}\text { Sinal } \\
\text { esperado }\end{array}$ \\
\hline Mercado de drogas & $\begin{array}{l}\text { Taxa para cada } 100 \\
\text { mil habitantes }\end{array}$ & DROGA & Positivo \\
\hline $\begin{array}{l}\text { Densidade de pessoas } \\
\text { por dormitório }\end{array}$ & \% da população & DORMI & Positivo \\
\hline $\begin{array}{l}\text { Famílias chefiadas por } \\
\text { mulheres }\end{array}$ & \% da população & MAES & Positivo \\
\hline Escolaridade de jovens & \% da população & ESCJO & Negativo \\
\hline Taxa de urbanização & \% da população & URBAN & Positivo \\
\hline Taxa de desemprego & \% da população & DESEM & $\begin{array}{l}\text { Positivo/ } \\
\text { negativo }\end{array}$ \\
\hline $\begin{array}{l}\text { Renda apropriada } \\
\text { pelos } 20 \% \text { mais pobres }\end{array}$ & $\begin{array}{l}\% \text { da renda total da } \\
\text { sociedade }\end{array}$ & QUINT & Negativo \\
\hline $\begin{array}{l}\text { Gastos per capita em } \\
\text { segurança pública }\end{array}$ & Gastos per capita & SEGUR & Negativo \\
\hline
\end{tabular}

Fonte: Elaboração própria.

Através da variável "mercado de drogas" é possível avaliar a contribuição da presença de atividades ilícitas lucrativas sobre as taxas de crimes letais intencionais nas unidades federativas brasileiras. Para se avaliar a influência dos aspectos socioeconômicos sobre a criminalidade violenta, optou-se pela escolha das variáveis de densidade de indivíduos por dormitório, famílias chefiadas por mulheres, taxa de urbanização, taxa de desemprego e o total da renda apropriada pelo primeiro quintil mais pobre da sociedade. Por fim, as variáveis de escolaridade de jovens e gastos per capita em segurança pública referem-se aos aspectos institucional e político, ou seja, avalia-se os esforços do Estado ao combate da criminalidade violenta no Brasil.

A fim de verificar se há o problema de multicolinearidade entre as variáveis explicativas, na Tabela 2 é apresentada a matriz de correlação entre elas.

unidades federativas brasileiras apresenta uma correlação alta com a taxa de urbanização. 
Tabela 2 - Matriz de correlação entre as variáveis

\begin{tabular}{lcccccccc}
\hline & DROGA & DORMI & MAES & ESCJO & URBAN & DESEM & QUINT & SEGUR \\
\hline DROGA & 1,000 & & & & & & & \\
DORMI & $-0,268$ & 1,000 & & & & & & \\
MAES & 0,175 & 0,183 & 1,000 & & & & & \\
ESCJO & 0,420 & $-0,223$ & $-0,033$ & 1,000 & & & & \\
URBAN & 0,498 & $-0,345$ & 0,261 & 0,421 & 1,000 & & & \\
\hline DESEM & $-0,333$ & 0,381 & 0,363 & $-0,352$ & $-0,011$ & 1,000 & & \\
QUINT & $-0,043$ & $-0,161$ & $-0,200$ & 0,140 & $-0,016$ & $-0,324$ & 1,000 & \\
SEGUR & 0,153 & 0,193 & 0,022 & 0,218 & 0,167 & 0,078 & 0,097 & 1,000 \\
\hline
\end{tabular}

Fonte: Elaboração própria a partir de dados da pesquisa.

Constata-se que não há colinearidade forte entre as variáveis selecionadas (ver Tabela 2), pois em termos absolutos os valores foram inferiores a 0,7 (GUJARATI; PORTER, 2011). Sendo assim, tais variáveis serão utilizadas no modelo econométrico deste estudo.

As informações das variáveis de taxas de crimes letais intencionais e as relacionadas ao mercado de drogas ${ }^{3}$ (posse, uso e tráfico) foram retiradas do Anuário Brasileiro de Segurança Pública (BRASIL, 2009; 2010; 2011; 2012; 2013). A densidade de indivíduos por dormitórios, o percentual de famílias chefiadas por mulheres, a frequência escolar ao ensino médio de jovens com idade de 15 a 17 anos, a taxa de urbanização, a taxa de desemprego e o total da renda apropriada pelo primeiro quintil mais pobre foram extraídas da PNAD (IBGE, 2008; 2009; 2011; 2012). Os valores dos gastos per capita em segurança pública das unidades federativas foram retirados da Secretária de Tesouro Nacional (BRASIL, 2014b), sendo que tais valores foram deflacionados para valores reais de 2012 pelo índice nacional de preços ao consumidor (INPC), elaborado e divulgado pelo (IBGE, 2014).

\section{Resultados e Discussão}

Para facilitar a discussão dos resultados, são utilizadas as abreviaturas das variáveis explicativas selecionadas ao longo do texto. As variáveis são: LETAL (taxas de crimes letais intencionais); DROGA (taxas de crimes relacionados ao mercado de drogas); DORMI (densidade de pessoas por dormitório); MAES (famílias chefiadas por mulheres); ESCJO (escolaridade de jovens); URBAN (taxa de urbanização); DESEM (taxa de desemprego); QUINT (renda total apropriada pelo primeiro quintil mais pobre); e SEGUR (gastos per capita em segurança pública).

O primeiro procedimento realizado foi o teste de simultaneidade de Hausman para verificar se a variável SEGUR é considerada endógena ao modelo econométrico proposto. Caso a variável seja endógena, os estimadores se tornam in-

3 As taxas de crimes relacionados ao mercado de drogas do Estado de Sergipe no ano de 2008 foi calculada a partir da média móvel das taxas desse mesmo tipo de crime nos anos de 2009, 2011 e 2012 dessa mesma localidade. 
consistentes e ineficientes (GUJARATI; PORTER, 2011). Pelo teste ${ }^{4}$ realizado, constatou-se que a variável SEGUR não é considerada endógena ao modelo proposto.

O segundo procedimento foi o da estimação do modelo econométrico na estrutura de dados em painel e a realização dos devidos testes para a escolha do melhor modelo (regressão pooled, efeitos fixos ou efeitos aleatórios) e para a correção de possíveis problemas como o de autocorrelação e heterocedasticidade. Na Tabela 3 são apresentadas as estimativas dos determinantes das taxas de crimes letais intencionais das unidades federativas, que foram empregadas na forma funcional de log-log. Nela constam as regressões pooled, de efeitos fixos e de efeitos aleatórios.

Tabela 3 - Estimativas dos determinantes das taxas de crimes letais intencionais das unidades federativas brasileiras

\begin{tabular}{|c|c|c|c|}
\hline \multirow{2}{*}{ Variável } & \multicolumn{3}{|c|}{ Modelo } \\
\hline & Regressão pooled & Efeitos aleatórios & Efeitos fixos \\
\hline DROGA & $0,095 * * *(0,051)$ & $0,157 *(0,001)$ & $0,162 *(0,002)$ \\
\hline DORMI & $-0,365^{*}(0,000)$ & $-0,384^{*}(0,005)$ & $-0,575 * *(0,019)$ \\
\hline MAES & $-0,270(0,507)$ & $-0,315(0,374)$ & $-0,904 * *(0,048)$ \\
\hline ESCJO & $-1,974(0,131)$ & $-0,912(0,126)$ & $-0,094(0,132)$ \\
\hline URBAN & $-1,974^{*}(0,000)$ & $-1,999 * *(0,014)$ & $1,766(0,688)$ \\
\hline DESEM & $0,523 *(0,006)$ & $0,376 * *(0,011)$ & $0,275^{* *}(0,085)$ \\
\hline QUINT & $-0,767(0,012)^{* *}$ & $-0,292(0,351)$ & $-0,078(0,831)$ \\
\hline SEGUR & $\begin{array}{c}0,482 \\
(0,599)\end{array}$ & $0,008(0,915)$ & $-0,051(0,560)$ \\
\hline CONSTANTE & $12,838^{*}(0,000)$ & $12,986 *(0,000)$ & $-0,583(0,975)$ \\
\hline $\begin{array}{l}\mathrm{R}^{2} \\
\text { OBS } \\
\text { Teste F (Chow) } \\
\text { Teste Breusch-Pagan } \\
\text { Teste de Hausman } \\
\text { Teste de Wooldridge } \\
\text { Teste de Wald }\end{array}$ & $\begin{array}{c}0,3031 \\
105\end{array}$ & $\begin{array}{c}0,2434 \\
105 \\
49,40^{*}\end{array}$ & $\begin{array}{c}0,2801 \\
105 \\
9,58 * \\
62,89 * \\
4,890 * * \\
4.207,78 *\end{array}$ \\
\hline
\end{tabular}

Fonte: Elaboração própria a partir de dados da pesquisa.

Nota: * $1 \%$ de significância; * * 5\% de significância; * * $10 \%$ de significância. Para os modelos de efeitos fixos e efeitos aleatórios é utilizado o $R^{2}$ do within groups.

$4 \quad$ O teste foi realizado de acordo com os procedimentos recomendados por Gujarati e Porter (2011, p. 697-698). 
Por meio dos testes $F$ de Chow e de multiplicador de Lagrange de Breusch-Pagan constatou-se que as características não observadas afetam as taxas de crimes letais intencionais das unidades federativas (ver Tabela 3). Nessa situação, as estimativas provenientes do modelo de regressão pooled são inconsistentes e viesadas.

Dada a existência da heterogeneidade, aplica-se o teste de Hausman para se verificar se o componente não observado é correlacionado com as variáveis explicativas. Os resultados do teste de Hausman indicaram a presença da correlação entre os termos. Logo, o modelo mais adequado é o de efeitos fixos (ver Tabela 3). Para Santos e Kassouf (2007), é apropriada a utilização de modelos de efeitos fixos em estudos que avaliam os determinantes da criminalidade, pois características locais, como o nível cultural, o modo de como os conflitos pessoais são resolvidos pelos indivíduos, entre outros fatores, podem afetar as taxas de crimes das localidades analisadas.

O modelo a ser utilizado para a discussão dos resultados foi o de efeitos fixos. No entanto, é necessário que sejam realizados os testes para a verificação dos problemas de autocorrelação e heterocedasticidade. Pelos testes de Wooldridge (autocorrelação) e Wald (heterocedasticidade) foram detectados os dois problemas (ver Tabela 3). A correção desses problemas foi realizada através de uma nova estimação do modelo escolhido com erros padrões robustos, conforme recomendado por Greene (2003). Os resultados são apresentados na Tabela 4.

Tabela 4 - Estimação do novo modelo de efeitos fixos com a correção dos problemas de heterocedasticidade e autocorrelação

\begin{tabular}{cc}
\hline \multirow{2}{*}{ Variável } & Modelo \\
\cline { 2 - 2 } DROGA & Efeitos fixos \\
DORMI & $0,162 * *(0,021)$ \\
MAES & $-0,575(0,245)$ \\
ESCJO & $-0,904 * * *(0,075)$ \\
URBAN & $-0,094(0,239)$ \\
DESEM & $1,766(0,640)$ \\
QUINT & $0,275^{* * *(0,059)}$ \\
\hline SEGUR & $-0,078(0,803)$ \\
CONSTANTE & $-0,051(0,439)$ \\
R & $-0,583(0,974)$ \\
OBS & 0,2914 \\
\end{tabular}

Fonte: Elaboração própria a partir de dados da pesquisa.

Nota: * $1 \%$ de significância; * $5 \%$ de significância; ** * $10 \%$ de significância. Para o modelo de efeitos fixos é utilizado o $R^{2}$ do within groups. 
Os resultados alcançados indicaram que a variável DROGA contribui para a ocorrência da criminalidade violenta nas unidades federativas brasileiras. Isso corrobora os resultados de trabalhos como o de Grogger e Willis (1998), Blumsteim (1995), Rios (2008), Robles, Calderón e Magaloni (2013), Dubourg e Prichard (2007), Beato Filho e Reis (2000), Santos e Kassouf (2007) e Uhr e Ziero (2011) de que a presença do mercado de drogas em determinadas localidades contribui para o agravamento de outras modalidades de crimes, como, por exemplo, os contra a pessoa e o patrimônio.

Em relação ao Brasil, o país se inseriu no fluxo do narcotráfico internacional, respondendo tanto a estímulos do mercado externo, quanto a fatores e circunstâncias de ordem local. As características estruturais do narcotráfico no país desenvolveram-se a partir do final da década de 1970 e, desde então, vários pontos do território nacional vêm sendo utilizados para trânsito de drogas ilícitas produzidas em outros países da América do Sul em via para outros continentes. Essa característica de abrigar uma atividade-meio em relação ao processo produtivo (trânsito de drogas) fez com que os grupos de criminosos nacionais, atuantes nos negócios de narcotráfico, permanecessem vinculados às estruturas e organizações nas duas pontas, com produtores e com consumidores. A vizinhança com produtores de cocaína (Colômbia e Bolívia) e a existência de uma infraestrutura de transportes e de comunicações fizeram do Brasil uma rota privilegiada para o tráfico internacional de drogas (BRASIL, 2005).

Vale citar que no Brasil a maior parte das mortes relacionadas ao mercado de drogas é concentrada principalmente em jovens do sexo masculino com idade de até 25 anos (ZALUAR, 2007). De acordo com Lima, Silva e Almeida. (2011), fatores como a situação de dificuldades financeiras na família, o desemprego, a influência de amigos e a atratividade financeira da atividade ilegal contribuem para que o indivíduo ingresse no mercado de drogas de modo a obter uma melhora na qualidade de vida.

Por sua vez, outro importante aspecto a ser destacado é a relação entre o mercado de drogas e a delinquência juvenil. Em 2011, a segunda categoria de ato infracional ${ }^{5}$ mais cometida no país por jovens infratores foi o de tráfico de drogas, com um valor correspondente a $26,6 \%$ do total de atos infracionais registrados (BRASIL, 2013a). Dessa forma, reitera-se a importância de intervenções do Estado ao combate ao tráfico de drogas no país, de modo a se tentar reduzir a expansão da criminalidade violenta no Brasil.

A variável DORMI é relacionada à Teoria da Desorganização Social. Tal abordagem teórica considera que pessoas que vivem em situação de "congestionamento familiar" são mais predispostas ao ato criminoso. No entanto, a relação

$5 \quad$ Ato infracional é o ato condenável, de desrespeito às leis, à ordem pública, aos direitos dos cidadãos ou ao patrimônio, cometido por crianças ou adolescentes (BRASIL, 2013a). 
esperada não foi alcançada e a variável não obteve significância estatística no modelo em questão.

A variável MAES é outra atribuída à Teoria da Desorganização Social. A hipótese de que os indivíduos que convivem em ambientes familiares conturbados são mais predispostos ao crime foi rejeitada. Esse resultado também foi encontrado por Santos (2009). Para o autor, no Brasil é crescente o número de separações e divórcios de casais, tornando-se comum que muitas crianças e adolescentes convivam somente com um dos pais e receba o apoio financeiro (a lei que garante a pensão alimentícia é uma das poucas aplicadas com rigor no país) e emocional do outro genitor que não possui a guarda legal. De acordo com o IBGE (2012), no período de 2000 a 2010, a quantidade de famílias chefiadas por mulheres no Brasil elevou-se de 22,2\% para 37,3\% em relação ao total de famílias brasileiras.

Pode-se atribuir outra justificativa para a discussão da relação encontrada entre as variáveis MAES e LETAL. Em 2005, o governo federal criou o Sistema Único de Assistência Social (Suas), que tem por intuito a prestação de serviços de assistência social e de cidadania aos brasileiros. A sua principal forma de atuação é por meio dos Centros de Referência de Assistência Social (Cras). No Quadro 1 são apresentados os principais tipos de serviços e assistência prestados por esses centros.

Quadro 1 - Tipos de serviços prestados pelos Cras

\begin{tabular}{|l|l|}
\hline \multirow{5}{*}{ Serviços } & $\begin{array}{l}\text { a) Socioeducativo geracionais, intergeracionais e com famílias; } \\
\text { b) Sociocomunitário; } \\
\text { c) Reabilitação do cidadão na comunidade em que vive; } \\
\text { d) Reabilitação de ex-usuários de drogas ilícitas. }\end{array}$ \\
\hline Benefícios & $\begin{array}{l}\text { a) Transferência de renda (Bolsa Família); } \\
\text { b) Transferência de renda (outros); } \\
\text { c) Benefícios de Prestação Continuada; } \\
\text { d) Benefícios eventuais: assistência em espécie ou material; } \\
\text { e) Outros. }\end{array}$ \\
\hline Programas & $\begin{array}{l}\text { a) Capacitação e promoção da inserção produtiva de jovens e } \\
\text { e projetos } \\
\text { b) Promoção da inclusão produtiva para beneficiários do } \\
\text { programa Bolsa Família e no Benefício de Prestação }\end{array}$ \\
& $\begin{array}{l}\text { c) Projetos e programas de enfrentamento à pobreza e fome; } \\
\text { d) Grupos de geração de trabalho e renda para as famílias } \\
\text { locais; } \\
\text { e) Outras atividades. }\end{array}$ \\
\hline
\end{tabular}

Fonte: BRASIL (2012). 
Até 2012, já haviam sido instaladas unidades dos Cras em aproximadamente 95\% dos municípios brasileiros, o que possibilitou expandir o acesso de tais serviços assistenciais ao longo do território nacional (BRASIL, 2012). Nesses centros são prestados serviços assistenciais a populações que vivem em áreas de vulnerabilidade socioeconômica, e dentre tais serviços destaca-se o assistencialismo prestado à recuperação de ex-usuários de drogas, sendo essa uma importante medida de prevenção do Estado para que tais jovens não ingressem novamente no mercado de drogas. Vale destacar também os demais tipos de serviços oferecidos por esses centros, como o de capacitação profissional e o de apoio ao cadastro aos programas sociais de transferência de renda direta.

Além disso, na maior parte dos casos, o acesso aos serviços e ações oferecidos nos Cras é por meio da procura espontânea das famílias e/ou indivíduos. O membro familiar que mais procura por tais serviços são as mães, pois são elas as quem possuem a maior preocupação com o bem-estar da família (OLIVEIRA, 2008). Sendo assim, tais serviços assistenciais do governo federal podem estar contribuindo para uma melhora da qualidade de vida das famílias que são chefiadas por mulheres no país, destacando-se, assim, a importância da expansão desse tipo de política para o combate da criminalidade violenta no Brasil. Por fim, vale citar que no estudo de Loureiro e Carvalho (2006) é encontrado um efeito positivo dos gastos governamentais em assistência social na redução das taxas de homicídios dos estados brasileiros.

Hirschi (1969) ressalta a importância da educação na contenção da delinquência juvenil. Para a variável ESCJO, a relação esperada foi alcançada, porém não foi significativa para o modelo. Já para a variável URBAN, a relação esperada também foi alcançada, porém o coeficiente dessa variável não alcançou significância estatística ao modelo em questão.

A variável DESEM apresentou uma relação positiva com as taxas de crimes letais intencionais das unidades federativas e obteve significância estatística. Tal resultado vem validar a hipótese apresentada por Becker (1968) de que o aumento na taxa de desemprego resultaria num aumento da criminalidade numa sociedade. Ou seja, em situações de dificuldades financeiras os indivíduos estariam mais dispostos ao ato criminoso de modo a obterem recursos para uma melhora na qualidade de vida. Essa constatação corrobora os resultados nds trabalhos de Miethe et al. (1991), Gould, Weinberg e Mustard (2002), Machin e Meghir (2004), Donohue e Levitt (2001), Sachsida et al. (2009) e Pereira e Fernandez-Carrera (2005). Desse modo, esse resultado destaca a importância da criação de novas oportunidades de empregos, principalmente para os mais pobres, de modo que tais indivíduos não optem pela criminalidade como um meio de obtenção de recursos.

Por fim, para as variáveis QUINT e SEGUR, a relação esperada foi alcançada, no entanto ambas não apresentaram significância estatística no modelo em questão. 


\section{Considerações Finais}

Objetivou-se com este estudo avaliar quais fatores estão associados à expansão da criminalidade violenta no país, representada aqui pelos delitos de homicídios, latrocínio e lesão corporal dolosa seguida de morte. Primeiramente, constatou-se a contribuição do crime organizado para o agravamento desse problema social, principalmente devido à expansão do mercado de drogas. Esse tipo de mercado ilícito é caracterizado principalmente pela violência que é gerada para a manutenção e continuidade das atividades que envolvem a produção e comercialização das drogas ilícitas no país. Dessa forma, medidas como aumento da vigilância e fiscalização nas fronteiras nacionais, aprimoramento e melhora da infraestrutura da polícia investigativa no país, identificação e policiamento dos locais de produção e comercialização de drogas, entre outras medidas relacionadas ao setor de segurança pública, devem ser adotadas pelo Estado de modo a conter a expansão do mercado de drogas no país.

Outra importante relação é o mercado de drogas e a delinquência juvenil, pois no Brasil as principais mortes relacionadas à comercialização de drogas ilícitas estão concentradas principalmente entre os jovens do sexo masculino com idade de até 25 anos. Os crimes relacionados ao tráfico de drogas se destacam entre as principais categorias de atos infracionais juvenis cometidos no país, fato ocasionado principalmente pela atratividade financeira dessa atividade ilícita. Dessa forma, abre-se a importância de medidas governamentais que visem o acesso de tais jovens a serviços como os de educação, cursos profissionalizantes, atividades socioeducativas, entre outras intervenções que venham instituir uma perspectiva de vida a esses jovens fora da criminalidade.

Além disso, constatou-se que a falta de oportunidades no mercado de trabalho tem contribuindo para o agravamento da criminalidade violenta no país. Ou seja, os indivíduos que estejam em situação de dificuldades financeiras têm encontrado na criminalidade (como por exemplo, o mercado de drogas) a oportunidade para a obtenção de recursos para uma melhora na qualidade de vida. Dessa forma, atribui-se a importância de políticas governamentais em prol da criação de novos postos de trabalho e de capacitação profissional, principalmente aos mais pobres, para que tenham mais chances de conseguir um emprego.

Na última década ocorreu um aumento na quantidade de domicílios chefiados por mulheres no país: de acordo com a literatura do crime, os indivíduos que crescem nesses tipos de ambientes familiares são mais propensos ao ato criminoso. No entanto, por meio dos resultados alcançados, observou-se uma relação negativa entre o percentual de domicílios chefiados por mulheres e as taxas de crimes letais intencionais das unidades federativas brasileiras. Nessa discussão, vale destacar que a mãe é o membro familiar que mais se preocupa com o bem-estar da 
família e, em situações de conflitos familiares, elas estão mais dispostas a buscar auxílio para a resolução dos problemas familiares. Com isso, abre-se espaço para a importância dos serviços socioassistenciais prestados pelos Cras localizados nos diversos municípios brasileiros. Tais serviços têm colaborado para a melhora da qualidade de vida de diversas famílias brasileiras que vivem em situação de vulnerabilidade socioeconômica (como, por exemplo, as que são chefiadas por mulheres) e, por consequência, tal intervenção governamental tem contribuído para a redução da criminalidade violenta no país. Portanto, recomenda-se a expansão desse tipo de política no país.

\section{Referências}

BALBO, M.; POSADAS, J. Una primera aproximación al crimen en Argentina. La Plata: Universidad Nacional de La Plata, oct. 1998. (Documento de Trabajo, n. 10).

BARBO, A. R. C.; SHIMBO, I. Uma reflexão sobre padrão mínimo de moradia digna no meio urbano Brasileiro. Revista Brasileira de Estudos Urbanos e Regionais, v. 8, n. 2, p. 75-94, 2006.

BEATO FILHO, C. C. Crime e cidades. Belo Horizonte: Editora UFMG, 2012.

BEATO FILHO, C. C.; REIS, I. A. Desigualdade, desenvolvimento socioeconômico e crime. In: HENRIQUES, R. (Org.). Desigualdade e pobreza no Brasil. Rio de Janeiro: IPEA, 2000.

BECKER, G. Crime and punishment: an economic approach. Journal of Political Economy, v. 76, p. 169-217, 1968.

BLUMSTEIM, A. Youth violence, guns and the illicit-drug industry. The Journal of Criminal Law and Criminology, v. 86, n. 1, p. 10-36, 1995.

BRASIL. Código Penal. Decreto-Lei no 2.848, de 7 de dezembro de 1940. Disponível em: $<$ http://www.planalto.gov.br/ccivil_03/decreto-lei/Del2848compilado.htm>. Acesso em: 20 jan. 2014.

. Ministério da Justiça e Segurança Pública. Secretaria Nacional de Segurança Pública. Anuário Brasileiro de Segurança Pública 2009. Disponível em: <http://www2. forumseguranca.org.br/novo/produtos/anuario-brasileiro-de-seguranca-publica/3oedicao >. Acesso em: 02 dez. 2013.

. Ministério da Justiça e Segurança Pública. Secretaria Nacional de Segurança Pública. Anuário Brasileiro de Segurança Pública 2010. Disponível em: <http://www2. forumseguranca.org.br/novo/produtos/anuario-brasileiro-de-seguranca-publica/4aedicao >. Acesso em: 02 dez. 2013.

Ministério da Justiça e Segurança Pública. Secretaria Nacional de Segurança Pública. Anuário Brasileiro de Segurança Pública 2011. Disponível em: <http://www2. forumseguranca.org.br/novo/produtos/anuario-brasileiro-de-seguranca-publica/5aedicao >. Acesso em: 02 dez. 2013. 
BRASIL. Ministério da Justiça e Segurança Pública. Secretaria Nacional de Segurança Pública. Anuário Brasileiro de Segurança Pública 2012. Disponível em: <http://www2. forumseguranca.org.br/novo/produtos/anuario-brasileiro-de-seguranca-publica/6aedicao >. Acesso em: 02 dez. 2013.

Ministério da Justiça e Segurança Pública. Secretaria Nacional de Segurança Pública. Anuário Brasileiro de Segurança Pública 2013a. Disponível em: <http://www2. forumseguranca.org.br/novo/produtos/anuario-brasileiro-de-seguranca-publica/7aedicao > . Acesso em: 02 dez. 2013.

. Ministério da Saúde. Base de Dados do Sistema Único de Saúde/DataSus. Disponível em: <http://www2.datasus.gov.br/datasus/index.php>. Acesso em: 03 abr. 2014a.

. Ministério da Saúde. Impacto da violência na saúde dos Brasileiros. 2005. Disponível $\overline{\mathrm{em}:}$ < http://www.sms.saude.gov.br/bvs/publicacoes/impacto_violencia.pdf > . Acesso em: 04 abr. 2014.

. Ministério do Desenvolvimento Social e Combate à Fome. Secretaria de Avaliação e Gestão da Gestão. Censo SUAS 2012. Brasília, DF: MDS, Secretaria de Avaliação e Gestão da Informação; Secretaria Nacional de Assistência Social, 2013b. Disponível em: <http:// aplicacoes.mds.gov.br/sagi/portal/403.php?url=http://aplicacoes.mds.gov.br/sagirmps/ ferramentas/docs/censo/CensoSUAS_2012_final.pdf>. Acesso em: 01 jun. 2014.

. Secretária do Tesouro Nacional. Tesouro transparente. Disponível em: <http://www. tesourotransparente.gov.br/ckan/dataset>. Acesso em: 04 maio 2014b.

BURSIK, R. J.; GRASMICK, H. G. Neighborhoods and crime: the dimensions of effective community control. New York: Lexington Books, 1993.

CANO, I.; SANTOS, N. Violência letal, renda e desigualdade social no Brasil. Rio de Janeiro: Sete letras, 2001.

CERQUEIRA, D.; LOBÃO, W. Determinantes da criminalidade: arcabouços teóricos e resultados empíricos. Dados - Revista de Ciências Sociais, Rio de Janeiro, v. 47, n. 2, p. 233269, 2004.

COHEN, L.; FELSON, M. Social change and crime rate trends: a routine approach. American Sociological Review, v. 44, n. 4, p. 588-608, 1979.

DONOHUE, J.; LEVITT, S. D. The impact of legalized abortion on crime. Quarterly Journal of Economics, v. 116, n. 2, p. 379-420, 2001.

DUBOURG, R.; PRICHARD, S. The impact of organized crime in the UK: revenues and economic and social costs. In: HOME OFFICE. Organised crime: revenues, economic and social costs, and criminal assets available for Seizure. London: Home office, 2007.

EHRLICH, I. Participation in illegitimate activities: a theoretical and empirical investigation. Journal of Political Economy, v. 81, n. 3, p. 521-565, 1973.

ENTORF, H., SPENGLER, H. Socioeconomic and demographic factors of crime in Germany: evidence from panel data of the German States. International Review of Law and Economics, v. 20 , n. 1 , p. $75-106,2000$. 
FAJNZYLBER, P.; ARAÚJO JÚNIOR, A. F. Violência e criminalidade. Belo Horizonte: UFMG, 2001. (Texto para Discussão, n. 162). Disponível em: < http://www.ospba.org/wp-content/ uploads/2012/04/Viol\%C3\%AAncia-e-Criminalidade.pdf>. Acesso em: 20 mar. 2014.

FAJNZYLBER, P.; LEDERMAN, D.; LOAYZA, N. Determinants of crime rates in Latin America and the world: viewpoints. Washington, D. C.: The World Bank, 1998.

GLAESER, E. L.; SACERDOTE, B. Why is there crime in cities? Journal of Political Economy, V. 107, n. 6 , p. 225-258, 1996.

GOULD, E. D.; WEINBERG, B. A.; MUSTARD, D. Crime rates and local Labor opportunities in the United States: 1979-1995. Review of economics and statistics, v. 84, p. 45-61, 2002.

GREENE, W. H. Econometrics analysis. New Jersey: Pearson Education, 2003.

GROGGER, J.; WILLIS, M. The emergence of crack cocaine and the rise in urban crime rates. The Review of Economics and Statistics, v. 82, n. 4, p. 519-529, 1998.

GUJARATI, D. N.; PORTER, D. C. Econometria Básica. Porto Alegre: Bookman, 2011.

HIRSCHI, T. Causes of delinquency. Berkeley: University of California Press, 1969.

IBGE. Pesquisa nacional por amostras de domicílios: ano 2008. Disponível em: < http://www. ibge.gov.br/home/estatistica/populacao/trabalhoerendimento/pnad2008/default.shtm >. Acesso em: (03) fev. 2014.

. Pesquisa nacional por amostras de domicílios: ano 2009. Disponível em: <http://www. ibge.gov.br/home/estatistica/populacao/trabalhoerendimento/pnad2009/default.shtm > . Acesso em: (03) fev. 2014.

. Pesquisa nacional por amostras de domicílios: ano 2011. Disponível em: <http://www. ibge.gov.br/home/estatistica/populacao/trabalhoerendimento/pnad2011/default.shtm > . Acesso em: 03 fev. 2014.

. Pesquisa nacional por amostras de domicílios: ano 2012. Disponível em: <http://www. ibge.gov.br/home/estatistica/populacao/trabalhoerendimento/pnad2012/default.shtm >. Acesso em: (03) fev. 2014.

Sistema nacional de índices de preços ao consumidor. Disponível em: <http://www. ibge.gov.br/home/estatistica/indicadores/precos/inpc_ipca/defaultinpc.shtm > . Acesso em: 02 fev. 2014.

KELLY, M. Inequality and crime. The Review of Economics and Statistics, v. 82, n. 4, p. 530$539,2000$.

LEMOS, A. A. M.; SANTOS FILHO, E. P.; JORGE, M. A. Um modelo para análise socioeconômica da criminalidade no município de Aracaju. Estudos Econômicos, v. 35, n. 3, p. 569-594, 2005.

LIMA, R. B. L.; SILVA, R. G.; ALMEIDA, E. S. Avaliação econômica do tráfico de drogas no estado do Acre. Redes, v. 16, n. 2, p. 102-130, 2011. 
LOBO, L. F.; FERNANDEZ-CARRERA, J. A criminalidade na região metropolitana de Salvador. Análise Econômica, v. 23, n. 44, p. 30-65, 2005.

LOUREIRO, A. O. F.; CARVALHO, J. R. Uma análise econométrica do impacto dos gastos públicos sobre a criminalidade no Brasil. Fortaleza: Laboratório de estudo da pobreza, 2006.

MACHIN, S.; MEGHIR, C. Crime and economic incentives. Journal of human resources, v. 39, n. 4, p. 958-979, 2004.

MARQUES, L. D. Modelos dinâmicos com dados em painel: uma revisão de literatura. Porto: Centro de Estudos Macroeconômicos e Previsão, 2000. (Texto para discussão, n. 100).

MIETHE, T. D.; HUGHES, M.; MCDOWALL, D. Social change and crime rates: an evaluation of alternative theoretical approaches. Social Forces, v. 70, p. 165-185, 1991.

NONNENBERG, M. J. B.; MENDONÇA, M. J. C. Determinantes dos investimentos diretos externos em países em desenvolvimento. Estudos Econômicos, v. 35, n. 4, p. 631-655, 2005.

OLIVEIRA, C. A. Criminalidade e o tamanho das cidades Brasileiras: um enfoque da economia do crime. In: ENCONTRO NACIONAL DE ECONOMIA, 33., 2005, Natal. Anais... Natal: Associação Nacional dos Centros de Pós-Graduação em Economia, 2005.

OLIVEIRA, C. T. Política de atenção à família: uma análise do Centro de Referência da Assistência Social em Guaraciaba - MG. 2008. 127 f. Dissertação (Mestrado em Economia Doméstica) - Universidade Federal de Viçosa, Viçosa, 2008.

PAIXAO, A. L. Crime, controle social e consolidação da democracia: as metáforas da democracia. In: REIS, F. N.; O`DONNELL, G. (Org.). A democracia no Brasil. São Paulo: Vértice, 1988.

PEREIRA, R.; FERNANDEZ-CARRERA, J. A criminalidade na região policial da grande São Paulo sob a ótica da economia do crime. Revista Econômica do Nordeste, v. 31, n. Especial, p. 898-918, 2000.

RESIGNATO, A. J. Violent crime: a function of drug use or drug enforcement? Applied Economics, v. 32, p. 681-688, 2000.

RIOS, V. Evaluating the economic impact of Mexico's drug trafficking industry. Cambridge: Harward, Spring 2008. (Working paper). Disponível em: < https://scholar.harvard.edu/files/ vrios/files/rios2008_mexicandrugmarket.pdf>. Acesso em: 21 fev. 2014.

ROBLES, G.; CALDERÓN, G.; MAGALONI, B. The economic consequences of drugtrafficking violence in Mexico. Stanford: Stanford University, 2013. (Povertyand Governance Series Working Paper). Disponível em: <https://cddrl.fsi.stanford.edu/sites/default/files/ RoblesCalderonMagaloni_EconCosts5.pdf>. Acesso em: 01 fev. 2014.

SACHSIDA, A. et al. Inequality and criminality revisited: further evidence from Brazil. Empirical Economics, v. 39, n. 1,·p. 93-109, 2009.

SAMPSON, R. J.; GROVES, W. B. Community structure and crime: testing socialdisorganization theory. The American Journal of Sociology, v. 94, n. 4, p. 774-802, 1989. 
SANTOS, M. J. Dinâmica temporal da criminalidade: mais evidências sobre o "efeito inércia" nas taxas de crimes letais nos estados Brasileiros. Revista Economia, v. 11, n. 1, p. 169-193, 2009.

SANTOS, M. J.; KASSOUF, A. L. Estudos econômicos das causas da criminalidade no Brasil: evidências e controvérsias. Revista Economia, v. 9, n. 2, p. 343-372, 2008.

. Uma investigação econômica da influência do mercado de drogas ilícitas sobre a criminalidade Brasileira. Revista Economia, v. 8, n. 2, p. 187-210, 2007.

SCHELLING, T. C. What is the business of organized crime? Journal of Public Law, v. 20, p. 71-84, 1971.

SERRANO-BERTHET, R.; CHIODA, L. Por um Brasil mais seguro: uma análise da dinâmica do crime e da violência. Revista Brasileira de Segurança Pública, v. 6, n. 1, p. 172-202, 2012.

SUTHERLAND, E. H. Development of the theory. In: SCHUESSLER, K. (Org.). Edwin H. Sutherland: on analyzing crime. Chicago: The University of Chicago Press, 1973.

UHR, D. A. P.; ZIERO, J. G. Teoria econômica do crime: evidencias do mercado de drogas sobre a criminalidade no Rio Grande do Sul. In: ENCONTRO DE ECONOMIA DA REGIÃO SUL, ANPEC-SUL, 14., 2011, Florianópolis. Anais... Florianópolis: Associação Nacional dos Centros de Pós-Graduação em Economia, 2011.

WOOLDRIDGE, J. M. Econometric analyses of cross section and panel data. Cambridge: MIT Press, 2002.

ZALUAR, A. Democratização inacabada: fracasso da segurança pública. Estudos Avançados, v. 21, n. 61, p. 31-49, 2007.

Recebido em: 27/11/2014. Aceito em: 21/09/2016. 